Letter to the Editor

doi:10.1017/\$1041610218000984

\section{Environmental factors influencing the link between APOE $\varepsilon 4$ and Alzheimer's disease (AD) risk}

While APOE $\varepsilon 4$ allele is considered a genetic risk factor for Alzheimer's disease (AD), no relation existed between APOE $\varepsilon 4$ and $\mathrm{AD}$ in the Yoruba in Nigeria among cohorts included in early prevalence waves. The authors' explanation that other disease susceptibilities may provoke earlier mortality is inconsistent with the Yoruba having a lower incidence of disease risk factors. Cohort enrichment in 2001 has altered the authors' conclusions; Yorba participants homozygous, and not heterozygous, for the $\varepsilon 4$ allele had significantly increased risk for $\mathrm{AD}(\mathrm{HR}=2.95, \mathrm{p}=0.0002)$ (Hendrie et al., 2014). This is a critical revelation, yet it is not clear why such a temporal relationship exists between risk genotypes and $\mathrm{AD}$ among the Yoruba. This letter proposes an explanation.

Economists have shown that the use of anthropogenic nitrogen fertilizers in agriculture drives structural economic changes and elevates non-agricultural labor productivity growth. The USA and Nigeria show major differences in the share of total nitrogen used that is synthetically derived, with increases in total nitrogen adoption and application in Nigeria accompanying crop yield gains since the 1980s (Lassaletta et al., 2014). The costs of such agricultural innovation remain and include environmental contamination. Nitrous oxide $\left(\mathrm{N}_{2} \mathrm{O}\right)$ is a modern health medicine, valued for its role as an inhalational anesthetic adjuvant/analgesic, though the compound also exists as a pervasive air pollutant, derived primarily from anthropogenic nitrogen use in agriculture.

Given that both population-based and molecular studies indicate that general anesthesia exposures, including $\mathrm{N}_{2} \mathrm{O}$, may increase caspase-3 activation and thereby elevate $\mathrm{AD}$ risk, we tested whether lagged county anthropogenic nitrogen is linked to age-adjusted $\mathrm{AD}$ mortality. County-level anthropogenic nitrogen use was determined by the United States Geological Survey (U.S.G.S.) (Gronberg and Spahr, 2012). County age-adjusted $\mathrm{AD}$ mortality rate was derived from the Centers for Disease Control and Prevention (CDC) (G30) (CDC, 2018). A two-way fixed effects regression analysis indicates that a ten-year lag logged measure of anthropogenic nitrogen among only counties $>75$ percentile in anthropogenic nitrogen use and controlling for non-farm use is significantly positively associated with the county age-adjusted AD mortality rate per 100,000 persons $(B=3.60$, S.E. $=1.52, \mathrm{p}$-value $<0.05, n=377$ counties, $T=17$ years, $N=3,270)$. Other criteria pollutants from the Environmental Protection Agency (EPA) showed no association with $\mathrm{AD}$ mortality rate (data not shown). These population-based data indicate that lagged county anthropogenic nitrogen used in agriculture (as valid $\mathrm{N}_{2} \mathrm{O}$ proxy) may be related to county age-adjusted $\mathrm{AD}$ mortality.

Postoperative cognitive decline among elderly exposed to inhalational, compared to intravenous, anesthetics was significantly higher, with a greater proportion of the former group showing reduced MMSE scores $(<25)$. Interestingly, the decline was strongly associated with APOE $\varepsilon 4$ (Cai et al., 2012). Moreover, total lipoproteins from APOE $\varepsilon 4 / 4$ sera appear to be less effective than total lipoproteins from other $\mathrm{APOE} \varepsilon$ variants in suppressing caspase 3/7 activity, a marker of apoptosis (DeKroon et al., 2003). Given that $\mathrm{N}_{2} \mathrm{O}$ induces caspase-3 activation (Zhen et al., 2009), it can be speculated that bearing the APOE $\varepsilon 4$ variant makes one less able to counter the effects of $\mathrm{N}_{2} \mathrm{O}$ (i.e. $\mathrm{N}_{2} \mathrm{O}$-induced caspase activation and nicotinic acetylcholine receptor dysregulation, as proposed; Fluegge, 2018). With evidence that the APOE $\varepsilon 4$ allele occurs more frequently in some sub-Saharan populations and yet only temporally contributes to dementia burden in developing economies, this suggests a contextual specificity of the allele's dominant role in $\mathrm{AD}$ pathology, representing a new gene-environment interaction. We suggest that unmeasured $\mathrm{N}_{2} \mathrm{O}$ emissions, predominantly derived from anthropogenic nitrogen use in agriculture, can be considered as a possible risk factor for dementia pathogenesis, especially $\mathrm{APOE} \varepsilon 4$ related $\mathrm{AD}$ incidence.

\section{Conflict of interest}

None.

\section{References}

Cai, Y. et al. (2012). Association between the apolipoprotein $\mathrm{E} 4$ and postoperative cognitive dysfunction in elderly patients undergoing intravenous anesthesia and inhalation anesthesia. Anesthesiology, 116, 84-93. doi:10.1097/ALN.0b013e31823da7a2.

Centers for Disease Control (CDC). (2018). CDC Wonder Online Databases. Available at: https://wonder.cdc.gov/; last accessed April 2018. 
DeKroon, R. M. et al. (2003). ApoE genotype-specific inhibition of apoptosis. Fournal of Lipid Research, 44, $1566-1573$

Fluegge, K. (2018). Tau protein levels in ADHD. Indian fournal of Clinical Biochemistry, doi:10.1007/s12291-018-0747-9.

Gronberg, J. M. and Spahr, N. E. (2012). County-level estimates of nitrogen and phosphorus from commercial fertilizer for the Conterminous United States, 1987-2006. U.S. Geological Survey Scientific Investigations Report, 2012-5207, p. 20.

Hendrie, H. C. et al. (2014). APOE $\varepsilon 4$ and the risk for Alzheimer disease and cognitive decline in African

Americans and Yoruba. International Psychogeriatrics, 26, 977-985. doi:10.1017/S1041610214000167.
Lassaletta, L., Billen, G., Grizzetti, B., Anglade, J. and Garnier (2014). 50 year trends in nitrogen use efficiency of world cropping systems: the relationship between yield and nitrogen input to cropland. Environmental Research Letters, 9, 1-9. doi:10.1088/1748-9326/9/10/105011.

Zhen, Y. et al. (2009). Nitrous oxide plus isoflurane induces apoptosis and increases $\beta$-amyloid protein levels.

Anesthesiology, 111, 741-752.

doi:10.1097/ALN.0b013e3181b27fd4.

\section{Keith Fluegge}

Institute of Health and Environmental Research, Cleveland, Ohio, USA

Email: keithfluegge@gmail.com 